\title{
Hospital Management using OAM [Operation Administration \& Maintenance] Tool
}

\author{
Rachana.R. Sanni, H. S. Guruprasad
}

\begin{abstract}
This paper proposes a software tool to monitor the system configuration for Hospital Management System. The OAM tool monitors the system configurations after the user installs it into the system. The aim of this software is to monitor the system about its configurations and install the required softwares to the respective system. There are four tools in this application, Fintal, Piston, Naavi and Mapel. To install these, a technique of single file installation using batch scripting is used. Batch scripting is used to execute the installation files of softwares and the softwares are installed. These installation files of softwares will be embedded as execution commands in a single file called "windows batch file", which should be saved with the extension as ".bat". The installation that starts will be displayed in the command prompt to know whether the softwares are getting installed correctly. After each installation, the configuration and initialization of installed softwares will be displayed. The required softwares are to be installed. Each of these performs particular tasks that are required for the management of Hospitals. Fintal is used for overall management of Hospital. This is the most user-friendly part of OAM Tool. This handles overall administrative part of Hospitals. Piston is used for storing patient's details. This stores the patients' reports in detailed manner of each test the patient has undergone. Naavi is used for storing Laboratory details. The tests of each patient are stored here. And the last one, i.e., Mapel which is used for storing pharmaceuticals details (Medicines). It stores the details of medicines such as from which pharmaceuticals the medicines are purchased. The license of the hospital is also stored in this part of OAM Tool. All these together form an OAM Tool. This tool also manages other required softwares like, MySQL, $O D B C$ drivers, etc. The management of Hospitals is very important as there is a need to maintain the patient details. This technique of installation is proposed in this paper to make the installation from hardware to remote installation such as, giving the access to the system in which the tool needs to be installed and to save the time of installation process.
\end{abstract}

Keywords: Batch scripting, Fintal, management of Hospital Mapel, MySQL, Naavi, OAM tool, ODBC drivers, patient details, Piston, system configurations, softwares.

\section{INTRODUCTION}

$\mathrm{T}$ he management of Hospitals is very necessary as there are many aspects that are to be carried out by the Hospital Staffs. Still, most of the Hospitals are following the manual

Manuscript received on July 28, 2021.

Revised Manuscript received on August 02, 2021.

Manuscript published on August 30, 2021.

* Correspondence Author

Rachana.R. Sanni*, M.Tech, Department of Information Science and Engineering, BMS College of Engineering, Bengaluru (Karnataka), India.

H. S. Guruprasad, PhD, Department of Computer Science and Engineering, BMS College of Engineering, Bangalore (Karnataka), India.

(C) The Authors. Published by Blue Eyes Intelligence Engineering and Sciences Publication (BEIESP). This is an open access article under the CC BY-NC-ND license (http://creativecommons.org/licenses/by-nc-nd/4.0/) method of writing the records using pen and paper and some are using the workstations to type the patient's records [1].

To address this, the paper proposes a software tool called "OAM (Operation Administration and Maintenance) tool" which is also called "Rakya Sunrise", this is helpful for monitoring what are the essential requirements for maintaining the systems in the hospitals.

OAM Tool contains a package of four tools. All the four tools together form a complete Tool. This product of Rakya Technologies is very helpful in the Hospital Management.

\section{REVIEW OF LITERATURE}

Generally, the hospital's mission is to enhance the efficiency by taking measures like reducing the patient's waiting time and giving improved quality treatments. Within these measures, HIS (Hospital Information Systems) is used for enhancing the efficiency and accuracy. The attention of increasing the number of hospitals is drawn by HIS [5].

In satisfaction of services regarding the health care, the relation of doctor and patients plays an important role [6]. The HPMS (Hospital Process Management System) was designed to detect the quality information indicators for hospitals and to model assessment methods for managing the processes and developing this system on the basis of quality of information management [26]. The Computerized Hospital Management System (HMS) is an automated system that is designed to manage the administration and information regarding patients. This provides information infrastructure and patient services [10].

Near Field Communication (NFC) based Hospital Real-time Patient Management System is used in multi speciality hospitals and super speciality hospitals to treat several cases that are distributed and dealt by different doctors [11]. The manual work of hospital staff can be minimized by using cloud which helps in saving time and efforts that can be put for any required IT systems [3]. The intelligent agents were deployed for designing the software (Hospital Management System). The agents are, Patient, Doctor, Nurse and Environment agents [22]. The Hospital Information System (HIS) is designed to provide medical services to patients. It is an efficient, patient-centered and high quality approach [4].

To protect the data of patients, a patient data management system for medical services and training was designed [24]. The Hospital Management System is necessary for managing the hospital's data and it is time saving [7].

Published By:

Blue Eyes Intelligence Engineering and Sciences Publication 
The Hospital-Pharmacy Management System was designed to prevent the large queues of patients at Pharmacies and Hospitals [12]. The HMS (Hospital Management System) product is used to store records of doctors in the database. It identifies the records having unique RFID tag. Digitally the prescriptions will be generated and on showing prescriptions, the drugs will be sold [8].

The System (Hospital Management System) was designed for managing the complete Hospital's transactions such as, details of availability of Doctors, complete information of IPD (In Patient Discharge) and OPD (Out Patient Discharge) patients, cost management, maintenance of rooms (ICU, VIP Rooms), laboratory tests, etc [18]. The System (HMS Hospital Management System) was designed for managing the operations of hospitals, such as, administration, patient care, cost management and profitability [16]. The patients will be given hardware kit to get the patient ID. This ID helps in tracking and monitoring of the patients, their details and equipments (medical equipments) used. Hence, the RFID are widely used [9]. The technology based on web was designed to minimize the manual work and to save time. This involves implementation of networking technology [13].

An integration of ICT (Information Communication Technology) is an important area of research since two decades. Radio Frequency Identification technology is used manner [23]. The E - Hospital Management System was designed to maintain the administration, cost maintenance, patient care and good profitability [25]. The E - Health Monitoring Architecture was designed with the purpose of storing data in a cloud as well as to monitor the patient privately [27].

The Advanced Hospital Management System was designed to maintain the patient's records. There is a database for storing the records, which prevents the loss of important records. The database has unique username and password to get accessed by the different panels (lab staff, admin, etc.). The admin is the first panel. The admin is responsible for updating the patient's records [14]. The Advanced Software was designed to overcome the old methods of management and reduce the consumption of additional time by the staff. Both the patient and staff were given a unique id and data will be stored automatically [15].

The HDMS (Hospital Database Management System) was designed for the Doctors to store their records. The database was implemented to store the details of the Doctors using MySQL and WAMP Software. This user interface has the facility to search the availability of the doctors and patient details using this system [17]. The Hospital Database Management System (HDMS) was designed and implemented effectively and efficiently to manage the hospital. The system was developed using softwares, MySQL, Apache and WAMP [28].

An intelligent hospital information management system was designed to provide the guidance for the patients at the nursing information management system (IHMS) was designed and implemented to provide the good quality treatments to patients and their families [20]. The hospital minimizes the work of staff and thus the RFID Applications widely for providing the services in reliable and secured entrance of the hospitals [19]. The hospital emergency

resource and patient management system based on real-time data capture and intelligent decision making was designed to provide visual simulation continuously and increase service levels and process efficiency [21].

\section{METHODOLOGY}

Software requirements specification -

The objective of this specification is to install this tool easily and to reduce the manual work of customers. The lists of requirements are as follows,

- Installation of tool in an easy way.

- The tool should be user friendly.

The software requirements are specified in particular. The versions of the softwares are also specified.

\section{A. Functional Requirements}

The functional specifications specify what softwares are required and the connections, interfaces among the softwares are as follows,

\section{MySQL Software}

This software provides facility to create various databases and stores the data in them. It has a structured query language which is also used to write queries and perform the data transactions. This software is used to store databases and it is important part of server as it will store all the details of registered patients and hospital.

\section{ODBC.NET Provider}

This provides access to ODBC data provider with the help of native ODBC drivers. It is the main software tool needed to provide access to ODBC. This software is used to provide access to connect the server with the connector.

\section{ODBC.NET Connector}

This provides connection (unique connection) to a data source which is created by DSN (ODBC Data Source Name) with a server or client database system. This software provides a connection between the server and the ODBC.NET connector.

\section{SAP Crystals}

These are the softwares which include the analytics for the purpose of reporting for small and midsized businesses. These are very important to view the reports. These also provide the features to design, edit, store and print the reports. This software has facility to be installed according to our system compatibility. (i.e., 32-bits, 64-bits, ubuntu, macOS, etc.) This software plays an important role in viewing the patient's receipts, altering the designs of receipts as per the requirement of the customers in different hospitals.

\section{Rakya Product Setup}

It is the company's software which is used to install the OAM tool. There is a requirement to install specific softwares before installing this setup file.

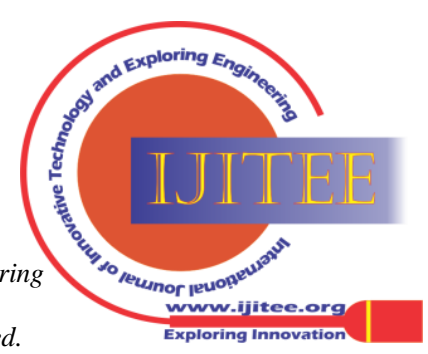


The softwares to be installed are, MySQL Server 5.0, ODBC.NET provider, ODBC.NET connector, SAP crystals. After these softwares are installed, then this setup needs to be executed. This file has the all four parts of OAM tool.

\section{Rakya Service Sandesh Slave}

This software is installed at the end after the installation of product setup file. We can install or skip to install this software. This is used for communication purpose.

\section{Visual Studio}

It is an IDE (Integrated Development Environment) from Microsoft. This software is used to build web apps, websites, mobile apps, developing the programs in different programming languages. This software is also used to view the report (receipt) patterns, edit and save the altered patterns. This software is used to alter the patterns of receipts according to the demands of the customers from different hospitals.

\section{SQLyog}

It is a tool (GUI tool) used for managing databases. The MySQL queries can be performed in this software to make any alterations in the databases.

\section{Batch Scripting}

It is a script file used to write windows batch file programs for various purposes such as, installation of softwares, programs for running applications, etc. It gets executed line-by-line when it is run. It is saved as filename (name of saved file) followed by the extension ".bat". There are various files designed using batch scripting. The language used is Python. This scripting file is very essential during the installation of this tool.

\section{Python Scripting}

It is a language which is easy to learn, having less number of lines of code, easy to implement, having easy syntax. It is a high-level (object-oriented, interpreted) programming language with dynamic semantics. It also reduces the cost of program maintenance. This language is used for coding as it involves less complexity and the importing of many packages is easy in this language.

The OAM Tool has some software requirements that are required for installation. The following Table- I shows the requirements,

Table- I: Software Requirements

\begin{tabular}{|c|c|}
\hline For Configuring MySQL & $\begin{array}{c}\text { MySQL Server - Version } \\
5.0 .67\end{array}$ \\
\hline For providing ODBC & ODBC.Net Provider \\
\hline $\begin{array}{c}\text { For connecting ODBC to } \\
\text { MySQL }\end{array}$ & $\begin{array}{c}\text { ODBC.Net Connector - } \\
\text { Version 5.1.5 }\end{array}$ \\
\hline For displaying Reports & $\begin{array}{c}\text { SAP Crystal Reports - Version } \\
13.0 .7 .1136\end{array}$ \\
\hline For installing OAM Tool & RakyaProductsSetup \\
\hline For installing Sandesh & RakyaSandeshSlave \\
\hline Slave & Visual Studio 2019- \\
\hline For Viewing/Editing & Community Version \\
\hline Reports & SQLyog \\
\hline
\end{tabular}

\section{B. Non-Functional Requirements}

These are the Non-Functional Requirements that specify how the implementation should be exactly done. The Non-Functional Requirements are as follows,

Productivity

Accomplishing the results as expected by the users is the quality of productivity. The installation of the tool should be successful without any errors and it should be customer friendly.

\section{Availability}

In OAM Tool, the application responsible for financial management of Hospitals (Fintal Application) is always available for using the Hospital's facilities. The installation of the tool can be done any time provided that there should be internet (wifi), the amount of storage needed for installation and the backup of Hospital's data should be taken correctly.

\section{Simplicity}

The installation of this tool has to be made as easy as possible. The customers should be easily able to install the tool. The system should be easily maintainable and manageable.

The implementation needs to be done after the design is ready. In the high level design, the design of the implementation needs to be done. The installation process has the following design as shown in the below Fig.5.1.a. and Fig.5.1.b.

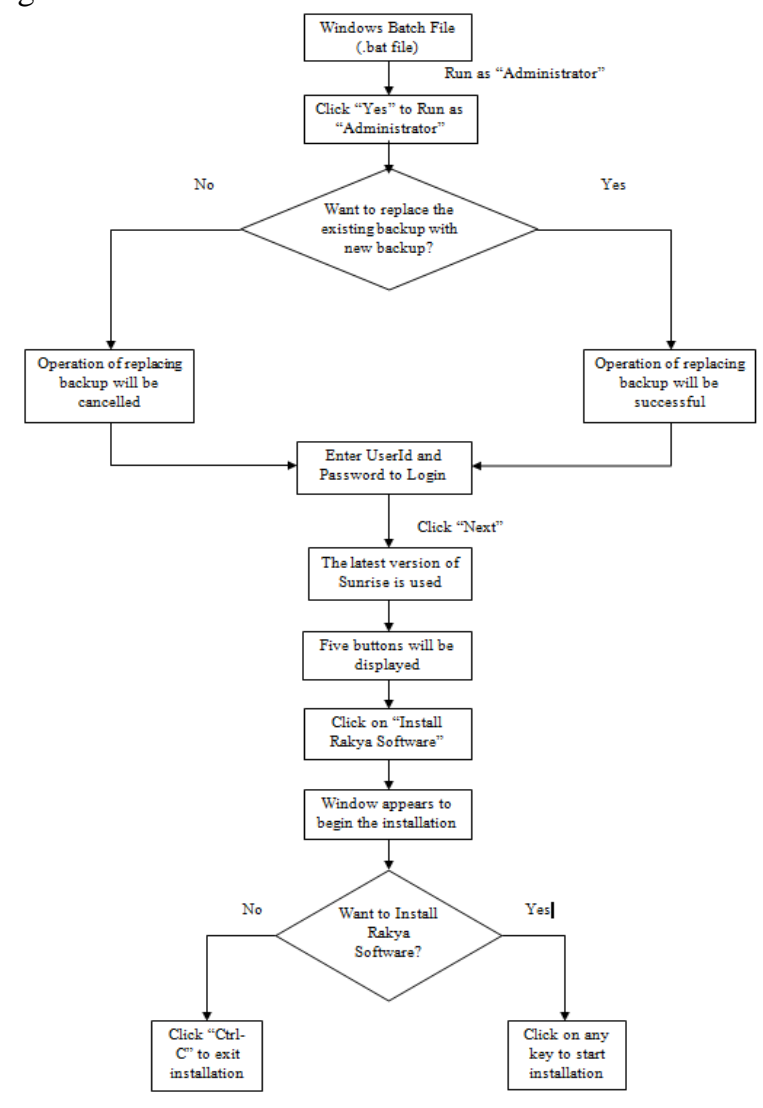

Fig 5.1.a: High Level Architecture of the Proposed System

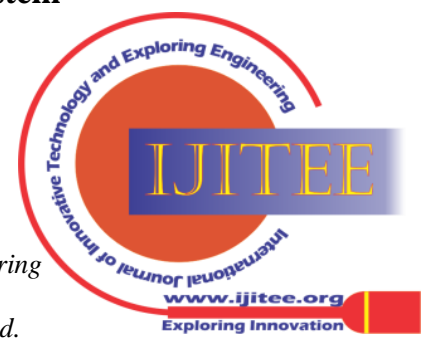




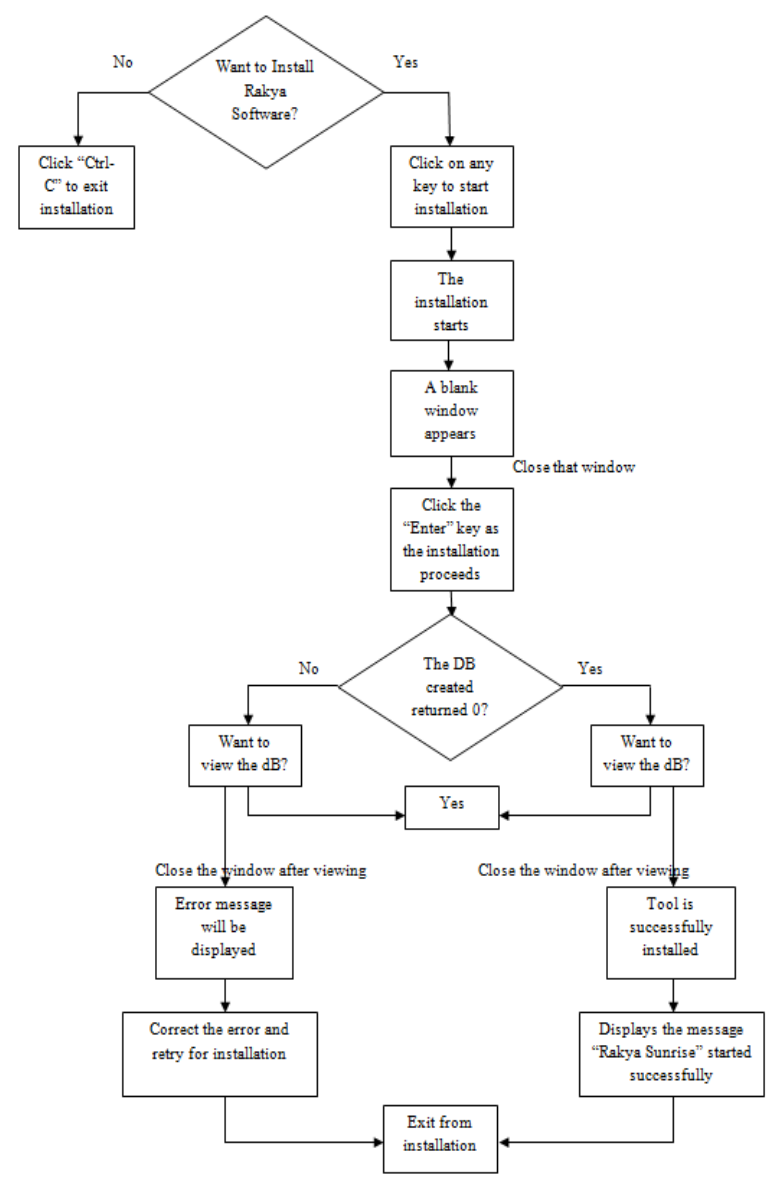

Fig 5.1.b: High Level Architecture of the Proposed System

\section{TESTING}

The Testing phase involves group of activities that are assigned for investing, examining the progress and quality of a project. Testing is done to check whether the output is derived as planned. If there are errors or any modifications to be made, then that part of work is done. After the corrections, it is re-tested whether it functions as desired.

The installation process of OAM Tool is tested so that the installation is done using the single file. The snapshots represent the installation process of OAM Tool which has Applications (Fintal, Piston, Naavi and Mapel) in it. To install the OAM Tool, this single file process is made as shown in the results.

\section{A. Testing Process}

The testing process has its own cycle like a project cycle. The testing process for the project is carried out so that the product should work correctly without errors. The errors that are present are fixed at an early stage of the project so that there shouldnot be any difficulties to fix the errors as the project progresses.

\section{B. Types of Testing}

In testing the implementation, the following test cases are carried out:

System Testing
In the System Testing, complete validation and integration of software product is tested. The purpose of this phase is to evaluate specifications of the system end-to-end. It is also called "Black Box Testing" which includes Functional and Non-Functional Testing.

Acceptance Testing

This testing is done after the System Testing. It is done by the client to test the machine before moving it to production environment. It is done in final phase of testing.

\section{ANALYSIS}

System Analysis is a crucial step in the project management. It is a step in which the components or organization are inspected in detail. The complex topics are split into smaller topics to understand it in a better way. The first and basic step is to understand the existing architecture. A design is proposed based on the analysis. The design involves the implementation structure which needs to be analyzed. The conclusion will be drawn based on the advantages and disadvantages (pros and cons) of the system. The analysis involves enhancing the backend development of the OAM Tool's installation.

\section{RESULTS}

The installation of OAM Tool involves single file execution. The single file is a CMD (command) file. This file contains the batch scripting to install Rakya Sunrise. This software is an encapsulation (It is the process in which the bundles and data are packed) of four applications, Fintal, Piston, Naavi and Mapel. The results of installation of Tool are as shown in the below Figures: Fig.2.1, Fig.2.2, Fig.2.3, Fig.2.4 and Fig.2.5.

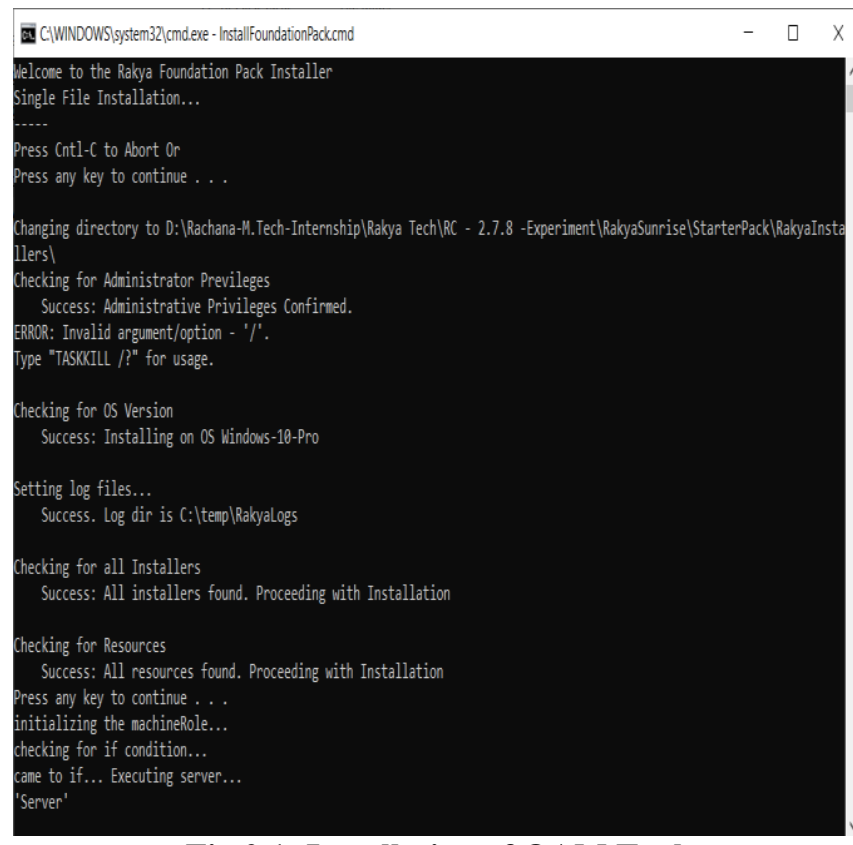

Fig.2.1: Installation of OAM Tool

Published By:

Blue Eyes Intelligence Engineering and Sciences Publication

(C) Copyright: All rights reserved.

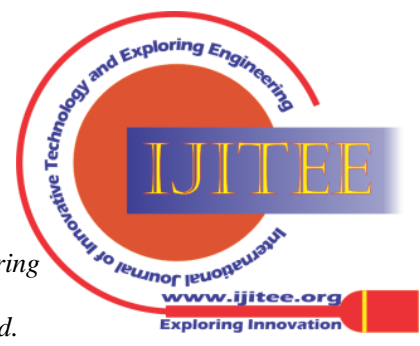




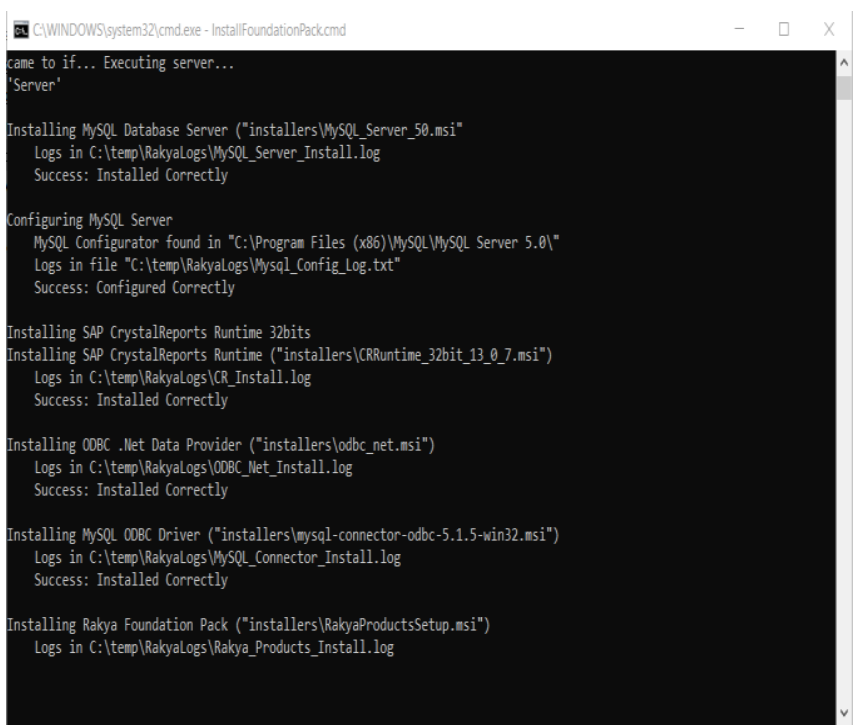

Fig.2.2: CMD showing the Installation of OAM Tool

Rakya DB Setup

?)

The DB Creation Script returned 0. Do you want to open the Installation log?

\section{Yes}

No

Fig.2.3: Database Creation Script

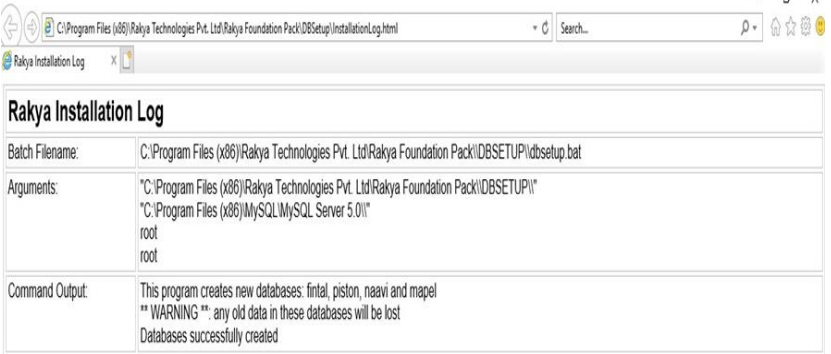

Fig.2.4: Installation Log showing created Databases

国

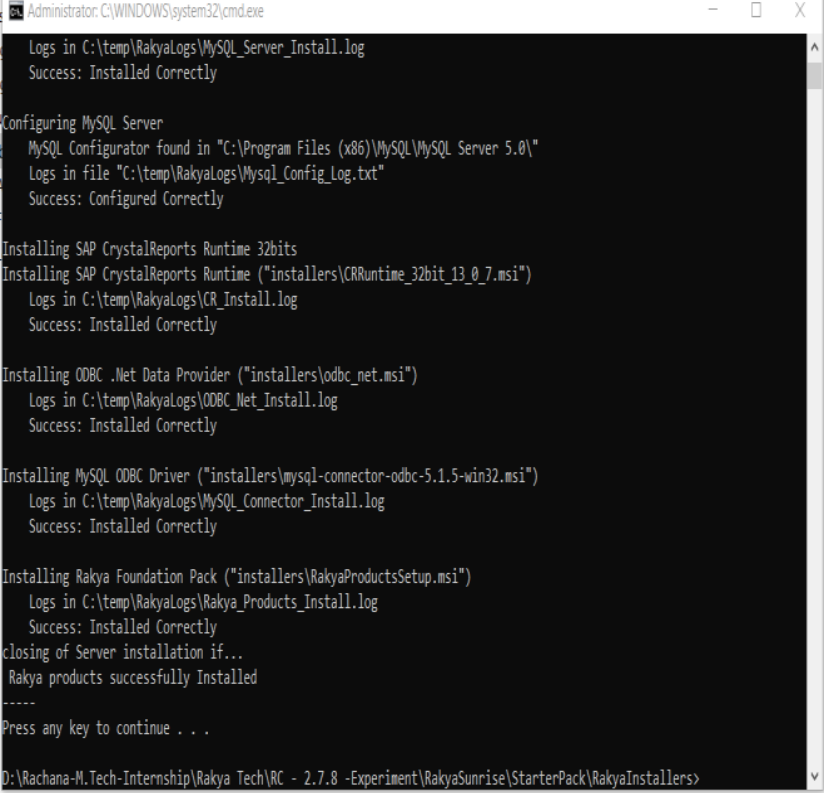

Fig.2.5: CMD showing the successfully Installed Rakya Sunrise

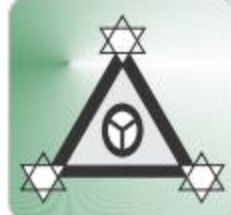

Fig.2.6: Fintal

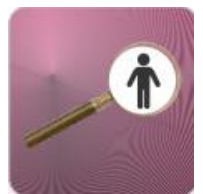

Fig.2.8: Naavi Fig.2.9: Mapel
The single file installation of OAM Tool is designed to install these Applications shown in Figures, 2.6, 2.7, 2.8, 2.9. These are used for Hospital management.

Table- II: Results of the Installation Process

\begin{tabular}{|c|c|c|c|}
\hline $\begin{array}{l}\text { Softwares to be } \\
\text { Installed }\end{array}$ & $\begin{array}{l}\text { Successful } \\
\text { Installed } \\
\text { Softwares }\end{array}$ & $\begin{array}{l}\text { Unsuccessful } \\
\text { Installed } \\
\text { Softwares }\end{array}$ & $\begin{array}{c}\text { Overall } \\
\text { Time } \\
\text { Consumed } \\
\text { for } \\
\text { Installation } \\
\text { Process }\end{array}$ \\
\hline $\begin{array}{l}\text { MySQL Server - } \\
\text { Version 5.0.67 }\end{array}$ & $\checkmark$ & - & \multirow{8}{*}{$\begin{array}{c}\text { Twenty } \\
\text { Minutes of } \\
\text { total time is } \\
\text { required for } \\
\text { the } \\
\text { complete } \\
\text { Installation } \\
\text { and } \\
\text { Initializatio } \\
\text { n of this } \\
\text { tool. }\end{array}$} \\
\hline ODBC.Net Provider & $\checkmark$ & - & \\
\hline $\begin{array}{l}\text { ODBC.Net Connector } \\
\text { - Version 5.1.5 }\end{array}$ & $\checkmark$ & - & \\
\hline $\begin{array}{c}\text { SAP Crystal Reports - } \\
\text { Version 13.0.7.1136 }\end{array}$ & $\checkmark$ & - & \\
\hline RakyaProductsSetup & $\checkmark$ & - & \\
\hline RakyaSandeshSlave & $\checkmark$ & - & \\
\hline $\begin{array}{l}\text { Visual Studio } 2019 \text { - } \\
\text { Community Version }\end{array}$ & $\checkmark$ & - & \\
\hline SQLyog & $\checkmark$ & - & \\
\hline
\end{tabular}

\section{CONCLUSION}

Since many years, Rakya Technologies has been working in the medical field in order to help the Healthcare Department. There are many versions of Sunrise available. They were installed using hardware procedures. At present, they are enhanced to install remotely (by giving access). To reduce the manual work, this Tool is being used by the Hospitals. The other facilities such as storing the backup of database, printing reports, etc, are well managed in this Tool. The installation of Sunrise has been achieved as per the expected results.

\section{REFERENCES}

1. Computer Science Major Sarjana Komputer Thesis, Even Semester Year 2007 / 2008, "SMALL CLINIC MANAGEMENT SYSTEM: PHARMACY AND INVENTORY SYSTEM”, by Anton Muliawan 0700675513, 08 THE - GROUP.

2. Jonny, Kriswanto, "Developing a Total Quality Management Model for Healthcare Industry: An Indonesian Hospital Case Study”, IEEE IEEM, 2017.

3. Chenghao He, Xi Jin, Zhanxiang Zhao, Tian Xiang, "A Cloud Computing Solution for Hospital Information System”, 2010 IEEE International Conference on Intelligent Computing and Intelligent Systems. and Sciences Publication

(C) Copyright: All rights reserved.

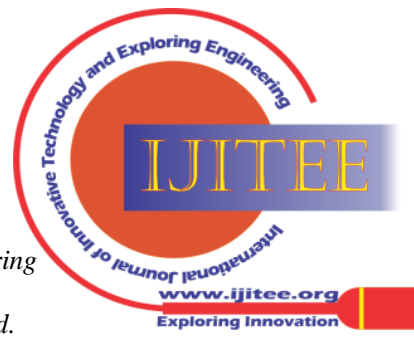


4. Roshidi Hassan, Megat Zuhairy and Megat Tajuddin, "Implementation of Total Hospital Information System (THIS) In Malaysian Public Hospitals: Challenges and Future Prospects", International Journal of Business and Social Research (IJBSR), Volume -2, No.-2, 2012.

5. Karim ZAROUR and Nacereddine ZAROUR, "A Coherent Architectural Framework for the Development of Hospital Information Systems“, LIRE laboratory, Department of Computer Science, University Mentouri of Constantine, BP 325, Route Ain El Bey 25017 Constantine, Algeria., VOL 31 NO 4 (2012), SECTION: ARTICLES, PAGES: 33-41.

6. ChangyongLiang DongxiaoGu FangjinTao Hemant K.Jain YuZhao BinDing, "Influence of mechanism of patient-accessible hospital information system implementation on doctor-patient relationships: A service fairness perspective“, Information \& Management Volume 54, Issue 1, January 2017, Pages 57-72.

7. Digvijay H. Gadhari, 2Yadnyesh P. Kadam, 3Prof. Parineeta Suman, "HOSPITAL MANAGEMENT SYSTEM", International Journal for Research in Engineering Application \& Management (IJREAM) ISSN: 2494-9150 Vol-01, Issue 11, FEB 2016.

8. S. Aswini Prathiba and Divya Jain, "Hospital Management System Using RFID", International Journal of Advance Research in Computer Science and Management Studies, ISSN: 23277821 (Online), Volume 3, Issue 3, March 2015.

9. Nellipudi.Siva Rama Krishna Prasad and Arepalli Rajesh, "RFID-Based Hospital Real Time Patient Management System", International Journal of Computer Trends and Technologyvolume3Issue3- 2012

10. Adebisi O.A, Oladosu D.A, Busari O.A and Oyewola Y.V, "Design and Implementation of Hospital Management System", ISSN: 2277-3754, ISO 9001:2008 Certified, International Journal of Engineering and Innovative Technology (IJEIT) Volume 5, Issue 1, July 2015.

11. Atluri Venkata Gopi Krishna, Cheerla Sreevardhan, S. Karun, S.Pranava Kumar, "NFC-based Hospital Real-time Patient Management System", International Journal of Engineering Trends and Technology (IJETT) - Volume4Issue4- April 2013.

12. A. Khelifi, D. Ahmed and N. Ali, "Hospital-Pharmacy Management System: A UAE Case Study“, Published 2013, Medicine, World Academy of Science, Engineering and Technology, International Journal of Computer, Electrical, Automation, Control and Information Engineering.

13. Pranjali Anpan, Roshni Udasi, Susneha Jagtap, Shon Thakre and Chalika Kamble, "Hospital Management System", International Research Journal of Engineering and Technology (IRJET) e-ISSN 2395-0056 Volume: 07 Issue: 04 | Apr 2020 www.irjet.net p-ISSN: 2395-0072.

14. Gunjan Yadav, Parth Lad, Parul Pandey and Tejaswi Kolla, "Advanced Hospital Database Management System", International Journal of Advanced Research in Computer and Communication Engineering Vol. 5, Issue 4, April 2016.

15. Kumaran S*, Dr Pusphagaran, Kalai Selvi, Christopher, Deepak, "A Study of Advanced Hospital Managaement System", IOSR Journal of Dental and Medical Sciences (IOSR-JDMS) e-ISSN: 2279-0853, p-ISSN: 2279-0861.Volume 16, Issue 2 Ver. III (February. 2017), PP 127-134 www.iosrjournals.org.

16. Olusanya Olamide.O, Elegbede Adedayo.W and Ogunseye Abiodun.A, "Design and Implementation of Hospital Management Using Java", IOSR Journal of Mobile Computing \& Application (IOSR-JMCA), e-ISSN: 2394-0050, P-ISSN: 2394-0042.Volume 2, Issue 1. (Mar. - Apr. 2015), PP 32-36 www.iosrjournals.org.

17. Amaechi James C., Agbasonu Valerian C., and Nwawudu Sixtus E., "Design and Implementation of a Hospital Database Management System (HDMS) for Medical Doctors", International Journal of Computer Theory and Engineering, Vol. 10, No. 1, February 2018.

18. "RDBMS- RELATIONAL DATABASE MANAGEMENT SYSTEM", reporting, system will use crystal reports for DOT Net 2005, far point spread sheet reporting tools provide backup (Manual /Automatic) to some other devices like hard Discs,.

19. Baki Koyuncu and Hakan Koyuncu, "Intelligent Hospital Computational Intelligence and Communication Networks (CICN).

20. Zhihong Liu, "Design and implementation of hospital emergency nursing information management system", 2016 International Conference on Smart City and Systems Engineering.

21. Ahmed Musa, Yahaya Yusuf, and Matthias Meckel, "A Hospital Resource and Patient Management System Based on Real-Time Data Capture and Intelligent Decision Making", 2012 International Conference on Systems and Informatics (ICSAI 2012). Management System (IHMS)”, 2015 International Conference on

22. Nidhi Kushwaha, Shashank Sahu and Rajesh Kumar Tyagi, "Evolving Intelligent Agents for Hospital Management System", 2013 3rd IEEE International Advance Computing Conference (IACC).

23. Nadeem Mahmood, Asadullah Shah, Ahmad Waqas, Zeeshan Bhatti, Adamu Abubakar and H. Abid M. Malik, "RFID based smart hospital management system: A conceptual framework", The 5th International Conference on Information and Communication Technology for The Muslim World (ICT4M).

24. Florin Daniel Anton and Silvia Anton, "A Patient Data Management System for Medical Services and Training", 2018 17th International Conference on Information Technology Based Higher Education and Training (ITHET).

25. Premkumar Balaraman and Kalpana Kosalram, "E -Hospital Management \& Hospital Information Systems - Changing Trends", I.J. Information Engineering and Electronic Business, 2013, 1, 50-58 Published Online May 2013 in MECS (http://www.mecs-press.org/).

26. Maria Ikram, Yan-ping Zhao and Ying Su, "Studying Hospital Process Management System Concerning Information Quality", Fourth International Conference on Cooperation and Promotion of Information Resources in Science and Technology.

27. Srijani Mukherjee and Koustabh Dolui, Soumya Kanti Datta, "Patient Health Management System using e-Health Monitoring Architecture", 2014 IEEE International Advance Computing Conference (IACC).

28. Amaechi James C., Agbasonu Valerian C., and Nwawudu Sixtus E., "Design and Implementation of a Hospital Database Management System (HDMS) for Medical Doctors", International Journal of Computer Theory and Engineering, Vol. 10, No. 1, February 2018.

\section{AUTHORS PROFILE}

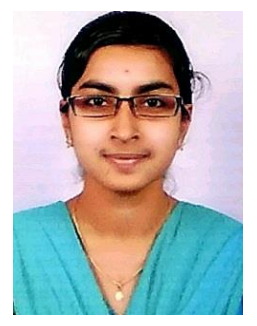

Rachana.R. Sanni Education Details -

$>$ M.Tech - Information Science and Engineering

BMS College of Engineering

Passed Year: Present Pursuing | Program Type: Full Time

BE - Information Science and Engineering Basaveshwar Engineering College, Bagalkot

Passed Year: 2019 | Program Type: Full Time

Publications -

$>$ Journal | Published on: March 2020

Rachana R. Sanni, "BANQUET HALL RESERVATION", International Research Journal of Engineering and Technology (IRJET) Volume 7, Issue 3, March 2020

https://www.irjet.net/volume7-issue3 S.NO:1011.

$>$ Conference Published on: Yet to be Published.

Rachana R Sanni, Ruksar Parveen and Dr. Ashok Kumar, "MEASURES TO SAFEGUARD COVID-19 PATIENT'S DATABASE"

Proceedings - Proceedings of the10th International Conference on Recent Engineering and Technology 21st June 2020, Bangalore, India.

Conference |Published on: Yet to be Published.

Rachana R Sanni and H. S. Guruprasad, "Analysis of performance metrics of heart failured patients using python and machine learning algorithms" in the Conference of ICCSA 2021.

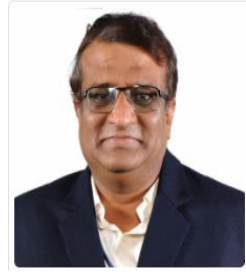

$$
\begin{aligned}
& \text { H. S. Guruprasad } \\
& \text { Education Details - } \\
& >\quad \text { PhD }- \text { Computer Science and } \\
& \text { Engineering } \\
& \text { Dr.MGR University, Chennai } \\
& \text { Passed Year: } 2010 \text { | Program Type: Part Time } \\
& >\quad \text { MS - Computer Science and Engineering } \\
& \text { BITS, Pilani } \\
& \text { Passed Year: } 1995 \text { | Program Type: Full Time }
\end{aligned}
$$

$>\mathrm{BE}$ - Computer Science and Engineering

Published By:

Blue Eyes Intelligence Engineering and Sciences Publication

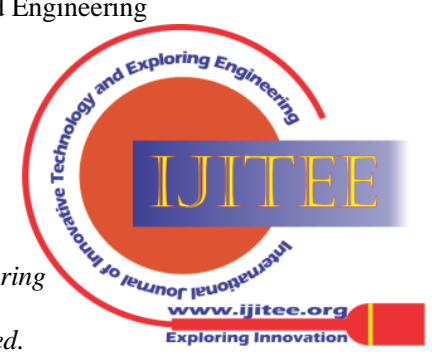


Mysore University

Passed Year: 1991 | Program Type: Full Time

\section{Publications -}

$>$ Journal | Published On : 01-04-2021

Sowmyashree A, H S Guruprasad, "Impact of Artificial Super Intelligence in Human Life", International Journal of Innovative Research in Applied Sciences and Engineering[IJIRASE], Volume 4, Issue 10, April 2021, pp 913 - 917. ISSN: 2456-8910, DOI: 10.29027/IJIRASE .v4.I10.2021.913-917.

$>$ Conference | Published On : 08-01-2021

Sindhu K, H.S. Guruprasad "Performance Improvement of Mobile Device using Cloud Platform", International Conference on Inventive Systems and Control (ICISC 2021), Jan 07-08th 2021, JCT College of Engineering and Technology, Coimbatore.

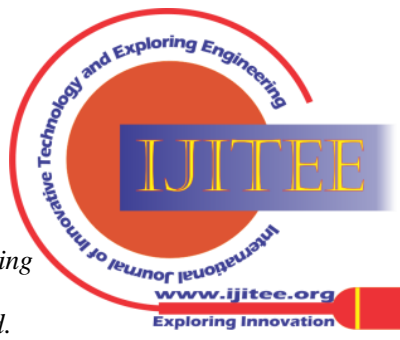

